\title{
EL ARRENDAMIENTO ANTE LA CORTE SUPREMA
}

\author{
Luis Pásara
}

Hacia fines de 1976, una serie de resoluciones de la Corte Suprema referidas a arrendamiento, han establecido criterios de interpretación que no sólo vinieron a alterar el status jurídico de esta relación contractual, sino que innovaron respecto a la interpretación misma.

A continuación se transcribe una selección de estas decisiones y, luego, se formula un comentario.

\section{Exp $1540-76$}

Lima

Lima, nueve de diciembre de

mil novecientos setentiseis

Vistos; y CONSIDERANDO: que el certificado de los Registros Públicos del Callao corriente a fojas seis, expedido a nombre de Graciela Burga Jaln, no puede entenderse referida a la actora $y$, de tratarse de un error, pudo salvársele oportunamente, máxime si la discrepancia la hizo notar el demandado en su escrito de fojas treintiocho; que el certificado otorgado por los Registros Públicos de Lima, que obra a fojas cinco, no arroja mérito definitivo, por contraerse a doña Graciela Burga Salvi, en tanto que la actora figura como Graciela Burga Larrea Salvi en el escrito de demanda y en los recibos de fojas tres, treintiuno, treintitrés y treinticuatro, que, de otro lado, la legislación de inquilinato tiene un carácter social y tiende a la protección del inquilino en vista de la escasez de viviendas, que, por tanto, para los efectos de calificar la nacesidad de la actora de ocupar el predio sub-litis, conforme lo requiere el Decreto Ley número veintiún mil ciento sesentiocho debe tenerse en cuenta su condición de soltera, la circunstancia de que sea dueña de un inmueble en el cercano balneario de San Bartolo y su calidad de condómira de otro bien raíz en la calle José Díaz de esta capital: declararon NO HABER NULIDAD en la sentencia de vista de fojas cincuentidós, 
su fecha veintidós de setiembre último, que revocando la apelada de fojas treintiséis, fechada el veinticinco de junio del año en curso, declara INFUNDADA la demanda, condenaron con las costas del recurso a la parte que la interpuso; en los seguidos por Graciela Burga Larrea con don Oscar Quiffónez Sifuentes sobre aviso de despedida y los devolvieron.

S.S. Figallo A. Carcía M. Tovar V. Saavedra.

Se publicó conforme a ley. Margarita Benites de Solís. Secretaria General.

$$
\text { Exp. } 162076
$$

Lima

Lima, diez de diciembre

de mil novecientos setentiséis.

VISTOS; y CONSIDERANDO : que la legislación de inquilinato tiene un fin social y propende a la protección del inquilino, en vista de la escasez de viviendas; que, por ello, para hacer lugar a las acciones de aviso de despedida por casa única no basta la prueba del dominio y el cumplimiento formal o aparente de los requisitos señalados en la Ley número diez mil ochocientos noventicinco y su Reglamento, sino que, como dispone el artículo primero del Decreto Ley numero veintiún mil ciento sesentiocho, se requiere que exista necesidad inmediata del propietario de habitar el predio cuya desocupación intenta; que en el caso de autos, según fluye de la solicitud de fojas cincuentidos y la certificacion de fojas cincuentitrés, el actor es persona de edad avanzada que mora en casa de uno de sus hijos que tiene familia; que de la escritura por la que el demandante adquirió el departamento sub-iudice, corriente en copia simple a fojas uno y siguientes, resulta que, al tiempo de la compra, en octubre de mil novecientos sesentiséis, aquél residía en el bien indicado, por lo que su decisión de mudarse a casa de su hijo debe ser atribuida a la imposibilidad o inconveniencia de conti. nuar viviendo en su propiedad: declararon HABER NULIDAD en la sentencia de vista de fojas cincuentiséis, su fecha veintisiete de agosto último, que revocando la apelada de fojas cuarentitrés, fechada el cuatro de junio del año en curso, declara fundada la demanda; reformando la primera y confirmando la segunda, declararon INFUNDADA dicha demanda; en los seguidos por Santiago Alosilla-Velasco Zamalloa con don José Reátegui Reátegui sobre aviso de despedida; $y$ los devolvieron.

S.S. Figallo A. García M. Tovar V. Saavedra

Se publicó conforme a ley Margarita Benites de Solís Secretaria General. 


\section{Exp. $1346-76$}

Lima

Lima, veintidós de diciembre

de mil novecientos setentiséis.

VISTOS; y CONSIDERANDO: que la legislación de inquilinato tiene carácter social, por cuanto su finalidad es proteger al inquilino en vista de la escasez de viviendas; que, además, la sentencia judicial se pronuncia hic et nunc sobre la situación de hecho al momento de la interposición de la demanda a la que se halla referida y sólo para la cual tiene validez el fallo; que, en consecuencia, los hechos en que se funda la demanda de aviso de despedida de casa habitación deben ser acreditados fehacientemente y la prueba instrumental debe demostrar que el actor al momento de interposicion de la demanda cumple los requisitos exigidos por la ley para que proceda la acción; que, según lo prescrito por el artículo primero del Decreto Ley número veintiưn mil ciento sesentiocho, el actor debe acreditar que el inmueble sobre el que versa la deman. da es la unica casa-habitacion de su propiedad y la necesita para habitarla; que los certificados de los Registros Publicos de Lima y Callao de fojas veintiocho y veintinueve han sido expedidos con fecha posterior a la interposición de la demanda, por lo que la demandante no ha acreditado que el inmueble sub-litis resulte su única casa-habitación a dicha fecha; que, de otro lado, la actora tampo. co ha probado que vive con carácter permanente en casa de su hijo; puesto que las certificaciones policiales domiciliares corrientes a fojas treinta y cincuentidós tendientes a demostrar que reside en Lima han sido contradichas por las constan cias policiales presentadas por la demandada a fojas treintiocho y cuarenta, que indican que ha residido en Arequipa hasta despues de la fecha de interposición de la demanda; que las instrumentales obrantes de fojas cincuentisiete a sesenti siete son insuficientes para probar la necesidad de residir en esta Capital y se refieren a una causal no invocada en la demanda mientras que no ha acreditado la existencia de otros familiares en Lima con quienes pretende vivir camo lo indica en ésta declararon HABER NULIDAD en la sentencia de vista de fojas setentiséis, su fecha veintitrés de agosto último que, revocando la apelada de fojas treinticuatro, fechada el veintinueve de marzo del affo en curso, declara fundada la demanda; reformando la primera, confïrmaron la segunda, que declara INFUNDADA la citada demanda; en los seguidos por dona Angelica viuda de Quiroga con doña Maria Aliaga Becerra, sobre aviso de despedida, y los devolvieron. Entre líneas: en esta - Vale.

S. S. Figallo A. García M. Saavedra P.

Se publicó conforme a ley. Margarita Benites de Solís. Secreatria General. 
Por los fundamentos pertinentes de la sentencia de vista; y CONSIDERANDO: que el artículo primero de la Ley número diez mil ochocientos noventicinco y el artículo primero del Decreto Ley número veintiún mil ciento sesentiocho establecen que la acción de aviso de despedida procede cuando se acredita a plenitud que el inmueble cuya desocupación se solicita es el único de propiedad del actor, requisito que ha sido cumplido en autos; que si bien es exigible se pruebe que, al momento de interponer la acción, el demandante de aviso de despedida es dueffo del bien cuya desocupación pretende to que se ha cumplido en el caso de autos- no es dable que ese criterio se aplique respecto de los requisitos simplemente negativos, vale decir de la prueba de no contar con otra casa-habitación en el lugar del juicio, tanto más si se tiene en cuenta lo normado en el artículo trescientos ocho del Código de Procedimientos Civiles y la inexistencia de mandato en tal sentido en las disposiciones legales que se ha citado y en el Reglamento contenido en el Decreto Supremo de dieciséis de noviembre de mil novecientos cuarentiocho; que los certificados policiales de fojas treintiocho y cuarenta no contienen indicación de haber comprobado la residencia de la actora en Arequipa y sólo se refieren a manifestaciones, en un caso de una trabajadora del hogar no identificada y en otra a una hija de aquélla, que no puede ser tal si se considera sus apellidos; que, por tanto, esa prueba no enerva el mérito del certificado policial de fojas treinta; que en todo caso, el hecho de que la demandada hubiese estado últimamente viviendo de modo alternado en Lima y en Arequipa, en casas de familiares cercanos, no le impide solicitar la desocupación de su única casa-habitación n la primera de esas ciudades, si existen motivos fundados para ello, es decir la necesidad a que alude el Decreto Ley numero veintiủn mil ciento sesentiocho; que a este último respecto, tratandose de una noción subjetiva, el Juzgador solo puede cuestionar la necesidad de habitar en la casa propia en casos ostensibles, que comporten un abuso del derecho; que en el presente proceso no puede concluirse que la demandantè no tenga esa necesidad si se considera las caracteristicas del inmueble sub-iudice y del contiguo de su hijo donde se halla alojada, la numerosa familia de dicho hijo -partidas de fojas cuarentiséis a cincuentiuno-y el continuado tratamiento médico a que está sometida, acreditado con la instrumental obrante de fojas cincuentisiete a sesentisiete; MI VOTO es porque se declare No Haber Nulidad en la sentencia de vista que, revocando la apelada, ampara la acción.

Sr. Tovar V.

Margarita Benites de Solís. Secretaria General. 
Lima, diecinueve de noviembre

de mil novecientos setentiséis.

VISTOS; con los acompañados; y CONSIDERANDO: que la sentencia judicial se pronuncia hic et nunc sobre la situación de hecho al momento de la interposición de la demanda a la que se halla referida y sólo para la cual tiene validez el fallo; que, en consecuencia, los hechos en que se funda la demanda de aviso de despedida de casa-habitación deben ser acreditados fehacientemente y la prueba instrumental debe demostrar que el actor, al momento de la interposición de la demanda, cumple los requisitos exigidos por la ley para que proceda la acción; que, como aparece de la demanda de fojas cuarentiséis, a la fecha de adquisición del inmueble cuya desocupación se pretende, el actor estaba casado, por lo que el certificado de fojas ocho, extendido sólo a nombre de aquél, es insuficiente para acreditar que el indicado inmueble es su única propiedad; que el certificado de fojas setenta, a nombre de la cónyuge del demandante, no convalida la situación expuesta al haberse otorgado después de interpuesta la demanda; que, además, el inmueble sub-iudice consta de dos casasthabitación, ocupadas por distintos inquilinos y sólo la sección segunda, signada con el numero cuatro. cientos cincuenticuatro, es la alquilada al demandado, contrayéndose a ella el juicio, como resulta de la declaración jurada de fojas siete, de la clausula segunda del contrato de fojas tres, del testimonio de poder que corre a fojas veintisiete de los acompañados, de la demanda misma de esos autos y del escrito de demanda del presente proceso (en el que se aprecia una visible e ineficaz enmendadura en el punto pertinente); que, por tanto, no se cumple tampoco en este caso el requisito de la casa-habitación única señalado por el Decreto Ley número vein. tiun mil ciento sesentiocho, que ha restrigido la facultad que acordaban la Ley. número diez mil ochocientos noventicinco y su Reglamento al propietario de un solo inmueble con varios departamentos o casas-habitación para solicitar la desocupación de uno cualquiera de ellos: declararon HABER NULIDAD en la sentencia de vista de fojas ochentidós, su fecha tres de setiembre último que, revocando la de primera instancia de fojas sesentinueve fechada el treintiuno de mayo del año en curso, declara fundada la demanda; reformando la primera y confirmando la segunda: declararon INFUNDADA la referida demanda de aviso de despedida interpuesta por don Carlos Alberto Rivas Plata Diaz contra don Fernando Céspedes Farfán; y los devolvieron.

S.S. Figallo A. García M. Tovar V. Dełgado V.

Se publicó conforme a ley. Margarita Benites de Solís. Secretaria General. 
La secretaria General de la Corte Suprema de Justicia, CERTIFICA: que los fundamentos del voto del señor Tovar Velarde son unicamente los siguientes: que el inmueble de propiedad del actor a que se refiere el certificado de fojas ocho, sito en la calle Leoncio Prado números cuatrocientos cincuenta y cuatrocientos cincuenticuatro, de Chiclayo, consta de dos casas habitación, ocupadas por distintos inquilinos y sólo la signada con el número cuatrocientos cincuenticuatro es la alquilada al demandado, contrayéndose a ella el juicio, como resulta de la declaración jurada de fojas siete, de la cláusula segunda del contrato de fojas tres, del testimonio de poder que corre a fojas ventisiete de los acompañados, de la demanda misma de esos autos y del escrito de demanda del presente proceso (en el que se aprecia una visible e ineficaz enmendadura en el punto pertinente); que, por tanto, no se curiple en este caso el requisito de la casa-habitación única sefralada por el Decreto-Ley número veintiún mil ciento sesentiocho, que ha restringido la facultad que acordaban la Ley número diez mil ochocientos noventicinco y su Reglamento al propietario de un solo inmueble con varios departamentos o casas-habitación para solicitar la desocupación de uno cualquiera de ellos.

Margarita Benites de Solís. Secretaria General.

Exp. 153876

Lima

Lima, veintiocho de diciembre

de mil novecientos setentiséis:

VISTOS; por los fundamentos de la sentencia de primera instancia; CONSIDERANDO: que constituye principio elemental de lógica jurídica en materia de prueba que ésta debe referirse a las situaciones de hecho en que se sustenta la demanda, las que, obviamente, son anteriores a ésta; que, asimismo, la carga de la prueba corresponde al actor a tenor de lo prescrito por el artículo trescientos treintisiete del Código de Proceđimientos Civiles, más aún, tratándose de normas que tutelan a la parte demandada como son las de inquilinato; que el certificado positivo del Registro de la Propiedad Inmueble solamente acredita que el actor aparece como propietario de un solo inmueble a la fecha de interposición de la demanda cuando ha sido expedido antes que ésta; que no debe confundirse el hecho que es objeto de la prueba con la oportunidad en que debe ser presentada; que, además, los instrumentos públicos cuya presentación exigen las normas legales para acreditar las preces de la demanda no significan el cumplimiento de un formalismo sin contenido real sino el medio de probar que el 
demandante cumple las exigencias de la ley al momento en que se interpone la demanda y el Juzgador debe compulsar su mérito sin exigir que el demandado deba acreditar su ineficacia subvirtiendo el caracter social de la ley, como lo ha hecho la recurrida; que si bien los instrumentos públicos pueden presentarse en cualquier estado de la causa en primera instancia, su merito es fechaciente cuando tienen la calidad de prueba pre-constituida; que el certificado de fojas cuarenta, otorgado el nueve de marzo del año en curso, no acredita que a la fecha de la demanda, presentada el tres del citado mes, el actor sólo tenf́a inscrito a su nombre el inmueble a que se refiere; que el certificado que corre a fojas setentidós, también otorgado después de la demanda, se diferencia del anterior solamente en que se indica que la "búsqueda ha sido hecha con treinta años de antigüedad", lo que debe hacerse en todos los casos para otorgar cualquier certificado positivo o negativo de propiedad y no acredita que el actor o su cónyuge solo hubiera tenido inscrito a su nombre el inmueble sub-iudice a la fecha de la demanda; que, en consecuencia, el demandante no ha acreditado que al interponerse la demanda reunía los requisitos que señala el Decreto Ley núme. ro veintiún mil ciento sesentiocho; declararon HABER NULIDAD en la sentencia de vista de fojas noventisiete, su fecha veintitrés de setiembre último; reformándola: confirmaron la apelada de fojas sesentiuno, fechada el catorce de junio del año en curso, que declara INFUNDADA la demanda; sin costas; en los seguidos por don Luis Marcaró Cárdenas con don Ricardo Vega Pérez, sobre aviso de despedida; y los devolvieron.

S.S. Figallo, García M. Saavedra

CONSIDERANDO: que el artículo primero de la Ley diez mil ochocientos noventicinco y el artículo primero del Decreto Ley número veintiún mil ciento sesentiocho establecen que la acción de aviso de despedida procede cuando se acredita a plenitud que el inmueble cuya desocupación se solicita es el único de propiedad del actor, requisito que ha sido cumplido en autos; que si bien es exigible se pruebe que, al momento de interponer la acción, el demandante de aviso de despedida es dueño del bien cuya desocupación pretende y vive en casa alquilada cuando menos desde un año antes de la iniciación del proceso lo que se ha cumplido en el caso de autos- no es dable que ese criterio se aplique respecto de los requisitos simplemente negativos, vale decir de la prueba de no contar con otra casa-habitación en el lugar del juicio, tanto más si se tiene en cuenta lo normado en el artículo trescientos ocho del Código de Procedimientos Civiles y la inexistencia de mandato en tal sentido en las disposiciones legales que se ha citado y en el Reglamento contenido en el Decreto Supremo de dieciséis de noviembre de mil novecientos cuarentiocho; que, además, el testimonio de fojas 
veinte y siguientes acredita que el inmueble sub-iudice es de interés social y ha sido adquirido por el actor con los fondos de un préstamo otorgado por su empleador el Seguro Social del Peru, lo que supone la previa investigación por esa entidad de que aquél no contaba con otra propiedad, como se reafirma con la estipulación de la cláusula décimo primera, según la que constituirá causal de rescisión destinar el inmueble a fin distinto al de la vivienda para el prestatario y sus familiares exclusivamente; que, por consiguiente, la pretensión del actor no solo responde a los requerimientos de la ley, sino que se adecúa al espíritu de la misma y a la política del Estado, encaminada a dotar de vivienda propia al mayor número de personas, especialmente a aquéllas de limitados recursos: MI VOTO es porque se declare No Haber Nulidad en la sentencia de vista que, revocando la apelada, declara fundada la demanda y ordena la desocupación.

Sr. Tovar V.

Exp. $1237-76$

Lima

Lima, veintinueve de octubre

de mil novecientos setentiséis

VISTOS; y CONSIDERANDO: que el enunciado individualista de "pacta sunt servanda", basado en la aparente igualdad entre las partes, no puede prevalecer en su rigor absoluto frente a los imperativos de la Justicia, que obligan a tener en cuenta las situaciones reales de desigualdad existentes dentro de la sociedad y que informa las normas de derecho social, womo las de inquilinato, las cuales, ante el desequilibrio económico, responden al principio de "pacta sunt dirimenda", que faculta al Juzgador para determinar y corregir el contrato, decidiendo la colision entre el interés individual y el social a favor del segundo; que, además, no es posible entender la común intención de las partes como dirigida a sustraerse a las limitaciones señaladas por la ley a la libertad de contratar; que el inmueble sub-litis es uno cuya distribución ha sido concebida para casa-habitación, según consta de la inspección ocular cuya acta corre a fojas diecinueve, por lo que al destinársele a vivienda no se ha desnaturalizado su finalidad; que, si bien a tenor del documento privado de fojas dieciséis, el departamento fue arrendado como local comercial, el plazo de ese contrato venció el treinta de setiembre de mil novecientos setentidós y la demanda ha sido interpuesta después de haber transcurrido más de tres años de dicho vencimiento, por lo que el actor no podía ignorar que no se le usaba como local comercial, puesto que los locales de esa naturaleza se encuentran abiertos al público, por lo que debe concluirse que consintió tácitamente en que fuera empleado como vivienda: declararon HABER NULIDAD en la sentencia de vista de fojas treintisiete, 
su fecha veintiséis de julio último, en la parte recurrida que, revocando la apelada de fojas veintiséis, fechada el diez de mayo del año en curso, califica el inmueble materia del juicio de local comercial; reformando la primera y confirmando la segunda en este extremo: declararon que el indicado inmueble es ca. sa-habitación; en los seguidos por don Guillermo Illanes Torino con don Policarpo Borja Ale, sobre desahucio; $y$ los devolvieron.

S.S. Figallo, García M. Tovar V. Delgado V.

Exp. 689-76

San Martín

Lima, treintiuno de agosto de

mil novecientos setentiséis.

VISTOS - con los acompañados; por sus fundamentos pertinentes; y CONSIDERANDO, además: que, si bien el artículo tercero del Reglamento de la Ley número diez mil ochocientos noventicinco, contenido en el Decreto Supremo de dieciséis de Noviembre de mil novecientos cuarentiocho, prescribe que el actor deberá probar que habita en casa-habitación alquilada en la misma localidad desde un año antes a la interposicion de la demanda y añade que a tal efecto deberá presentar los recibos correspondientes, además del certificado que le otorguen las autoridades de policía, no es procedente adoptar una interpretacion rígida de ese precepto reglamentario, porque pueden concurrir circunstancias especiales que impidan la presentación de tales recibos, porque debe atenderse a la finalidad y espiritu de esa norma y porque no es admisible la prueba tasada; que aunque el demandante solo ha presentado recibos por el lapso comprendido entre Noviembre de mil novecientos setenticuatro y Marzo de mil novecientos setenticinco inclusive (fojas dieciocho a veintidos, reconocidos a fojas once del incidente de tacha de documentos), ha acreditado con otros medios que desde mucho antes fue inquilino del inmueble de propiedad de don Antenor Rodríguez Ochoa a que aluden tales recibos, sito en el Jirón Gregorio Delgado número cuatrocientos cuarentiuno; que a este último respecto existen la constancia de fojas treintiuno, otorgada por el citado Rodríguez Ochoa, reconocida a fojas ciento noventa, la declaración circunstanciada del mismo Rodriguez Ochoa actuada a fojas cincuentinueve, los certificados policiales de fojas ciento ochentitrés de los principales y veinte del citado incidente de tacha y la copia certificada de la partida de defunción obrante a fojas veintiocho de ese mismo incidente: declararon NO HABER NULIDAD en la sentencia de vista de fojas doscientos veintiocho, su fecha veintiséis de Febrero del affo en curso, que confir- 
mando la de primera initancia de fojas doscientos dos, su fecha seis de Enero del propio affo, declara FUNDADA la demanda de aviso de despedida interpuesta a fojas seis por don Edmundo Rfos Padilla y, en consecuencia, dispone que don Jorge Saavedra del Aguila desocupe el inmueble materia de la litis en el término de cuatro meses; con lo demás que contiene; condenaron con las costas del recurso y la multa de seiscientos soles a la parte que lo interpuso; y los devolvieron.

S.S. Freyre V. Tovar V. Figueroa E. Delgado V.

\section{Exp. $739-76$}

Lima

Lima, diez de setiembre de mil novecientos setentiséis.

VISTOS; y CONSIDERANDO: que las leyes de inquilinato números diez mil doscientos veintidós y diez mil setecientos dieciseis aplicables a los contratos celebrados con anterioridad a la fecha que sefiala el articulo ciento veintisiete del Decreto Supremo número doscientos ochentisiete sesentiocho-HC, ratificado por Decreto- Ley número diecinueve mil novecientos cuarentiséis, son disposiciones de carácter social y por ende de orden público, cuyo debido cumplimiento ha de cautelar el organismo jurisdiccional; que dichas leyes no contemplan como causal de desahucio la de vencimiento de plazo; que en autos, a fojas dieciséis, se comprueba que las partes celebraron contrato de locación-conducción en fecha veintiocho de Febrero de mil novecientos sesentisiete, estipulándose en las cláusulas segurida y tercera un aumento progresivo de la merced conductiva, que nuevamente fue convenido el primero de Mayo de mil novecientos setenta at suscribirse las "cláusulas adicionales", según consta en la cláusuta sétima que corre a fojas quince; que en consecuencia si el aumento progresivo de la renta fue condičión del contrato firmado el veintiocho de Febrero de mil novecientos sesentisiete, no procede apreciar como un caso de novación objetiva el hecho de reiterarla el primero de Mayo de mil novecientos setenta ni menos ha habido novación subjetiva y por ello las "cláusulas adicionales" constituyen una prórroga que da lugar a la prolongación del plazo pero subsisten las demás condiciones fundamentales del contrato; que la interpretación de las sentencias inferiores conduce a calificar como novación cualquier modificación del monto de la merced conductiva sin advertir que en realidad no hay sustitución de una obligación por otra distinta, no se prođuce el cambio de objeto que exige la novación; que de otro lado la aludida interpretación implíca atribuir al locatario la voluntad de renunciar por anticipado al beneficio de las leyes de inquilinato y facilitar al 
locador una acción que no podfa promover, consiguiendo así por vía indirecta lo que la ley le prohibe directamente; que por lo expuesto corresponde estimar como fecha de celebración del contrato el veintiocho de Febrero de mil novecientos sesentisiete y de aplicación las leyes números diez mil doscientos veintidós y diez mil setecientos dieciséis: declararon HABER NULIDAD en la senten. cia de vista de fojas cincuentinueve, su fecha seis de Mayo del año en curso que, confirmando la de primera instancia de fojas cuarentiuno, su fecha doce de Enero del mismo año, declara fundada la demanda de fojas seis; reformando la primera y revocando la segunda: declararon INFUNDADA la demanda de desahucio interpuesta por đonfa Zelmira Santa María de Ramal contra don Manuel Laguna Elera; y los devolvieron.

S.S. Figallo, García M. Delgado V.

Se publicó conforme a ley. Margarita Benites de Solís. Secretaria General.

Por los fundamentos pertinentes de la recurrida y CONSIDERANDO, ade * más: que constituyen elementos esenciales del contrato de locación-conducción: la cosa, la renta, el plazo y el consentimiento; que, cuando la modificación se circunscribe al plazo tenemos la ampliación o prórroga del contrato, empero, si ella también comprende la renta, procediendo las partes en observancia de un pacto previo como el contenido en la segunda parte de la cláusula tercera, a establecer un plazo y renta diferentes a los que hasta entonces regian, hay que entender que su voluntad es la de volver a obligarse bajo distintas condiciones, dando nacimiento así a un nuevo contrato; que la particularidad de dejar subsistentes las restantes especificaciones del anterior contrato, carece de mayor significación, por tratarse no de previsiones esenciales sino secundarias que bien pudieran ser omitidas, porque en este supuesto, las prescripciones de la ley suple al silencio de las partes; por tales razones: Mi Voto es porque se declare No Haber Nulidad en la sentericia de vista que confirmando la apelada, declara FUNDADA la demanda.

S. Freyre V.

Margarita Benites de Solís. Secretaria General.

Exp. $1229-76$

Lima

Lima, dos de diciembre de

mil novecientos setentiséis

VISTOS; y CONSIDERANDO: que consta en autos, seguin prueba aportada por la actora a fojas veintidos y veinticuatro, que la firma "Vestitex Sociedad 
Anónima" se encuentra en proceso de liquidacion y que el negocio ha sido asumido por los trabajadores cooperativizados, bajo la denominación de "Cooperativa de Servicios Multiples Vesti-Coop Limitada", ocupantes del local sub-litis; que, por tanto, el litigio se circunscribe a determinar si el cambio operado en la conducción de dicho negocio constituye una cesión clandestina de arrendamiento, incursa en lo dispuesto por el artículo mil quinientos treintiuno, inciso cuarto, del Código Civil; que el Juez, cuya función es administrar justicia, no puede permanecer indiferente a los cambios que ocurren en la realidad donde actúa y, por el contrario, es su deber aplicar las leyes en armonía con esas transformaciones; que desde hace tiempo prevalece en la doctrina y en la legislación comparada el concepto de que la empresa es una comunidad de trabajo y que a ella concurren como sujetos esenciales empresarios y trabajadores, de donde resulta que el trabajador no es persona ajena a la empresa; que, asimismo, es oportuno tener presente que toda empresa, en cuanto es fuente de trabajo, cumple una función social, por lo que su adecuado desenvolvimiento interesa no sólo a sus componentes y a quienes mantienen relaciones con ella sino a la Sociedad, a cuyo bienestar coadyuva y por ende al Estado mismo; que el hecho de haber asumido los trabajadores la dirección de la empresa en la que prestaban servicios no se asimila al caso de una cesión de arrendamiento a favor de tercera persona extrafía al contrato de locación-conducción, sino más bien a la institución de la Sucesión, porque está probado que la firma Vestitex está por disolverse $y$ ha sido sucedida por sus trabajadores que venian ocupando el local objeto del desahucio organizados en una cooperativa para cumplir la misma finalidad; que, por consiguiente, no es de aplicación el artículo mil quinientos treintiuno; inciso cuarto, del Código Civil y el derecho de la Cooperativa a continuar en la locación pactada por Vestitex resulta amparable conforme al principio que informa el inciso tercero del mismo numeral: declararon HABER NULIDAD en la sentencia de vista de fojas cincuentiséis, su fecha siete de julio del año en curso que, revocando la apelada de fojas cuarenticinco, fechada el primero de abril del mismo ańo, declara fundada la demanda de desahucio interpuesta a fojas seis; reformando la primera y revocando la segunda, declararon INFUNDADA en todos sus extremos la referida demanda; en los seguidos por Inmobiliaria Víctor A. Rivera Sociedad Comercial de Responsabilidad Limitada con la Cooperativa de Servicios Múltiples Vesti-Coop Limitada y otra; y los devolvierún.

S.S. Figallo A. García M. Tovar V. Saavedra P.

Se publicó conforme a ley. Margarita Benites de Solrs. Secretaria General. 
La precedente muestra de resoluciones judiciales de 1976, mayormente referidas a aviso de despedida por casa única, y sobre la cual se ha trabajado el análisis que sigue, podría sugerir a una primera lectura la existencia de un com. portamiento errático de la Corte Suprema en el tratamiento del problema del arrendamiento. Mientras en un caso se rechaza la adopción de una interpretación rígida, en otros se argumenta con un legalismo severo para la admision de la prueba ofrecida por el propietario Más aún, a esa primera vista podria resultar desconcertante que se invoque la finalidad de la ley $\mathrm{y}$, simultáneamente, se use insistentemente el formalismo procesal para merituar las pruebas.

El primer problema pues, para comprender estas resoluciones sobre arrendamiento dotadas de un alto contenido innovador, es penetrar en el razonamiento judicial, alcanzar la ratio decidendi del juzgador. Si buscamos un punto de partida a través de los considerandos, el más frecuentemente repetido de ellos tiene relación con la finalidad de la legislación vigente; la formulación repetida es: "la legislación de inquilinato tiene un carácter social y tiende a la protección del inquilino en vista de la escasez de viviendas" (Exp. 1540-76). En algunos casos varía el fraseo, llegando a formulaciones que enfatizan más la protección legal del inquilino: "la legislación de inquilinato tiene carácter social, por cuanto su finalidad es proteger al inquilino..." (Exp. 1620-76). Así pues, parece estar en la finalidad de la ley -o mejor, en la interpretación que el juzgador hace de ella- el primer elemento integrante del razonamiento de estas sentencias.

Esta premisa sirve en todos los casos, pero se procesa mediante cuestiones más especificas. La muestra de resoluciones ofrece una serie de casos referidos al aviso de despedida por casa única $y$, luego, tres casos de interpretación contractual que examinaremos separadamente

En lo que se refiere al aviso de despedida, el análisis de casos revela una dicotomía Mientras en algunos de ellos se prioriza la comprobación de la necesidad efectiva del propietario, de acuerdo a lo dispuesto por el artículo primero del decreto-ley 21168 , en otros parece irse, más bien, a la búsqueda de los argumentos que resulten necesarios para amparar al inquilino Ambos puntos de partida son distintos y, como veremos, comportan razonamientos diversos y resultados contradictorios.

En el primer tipo de casos, el juzgador se coloca por encima de los requisitos formales preceptuados por la ley para probar la nécesidad, y va a la efectiva comprobación de ésta, apreciando con cierta libertad el mérito de la prueba ofrecida por la demandante. En un sentido contrario a la pretensión del actor, 
esto ocurre en los Exp. 1540-76 y 1620-76; en el primero se meritúa que la demandante es soltera, tiene una casa "en el cercano balneario de San Bartolo" y es condómina de otro inmueble en Lima; en el segundo se aprecia que el actor es "persona de edad avanzada que mora en casa de uno de sus hijos que tiene familia" $y$ el hecho que, al tiempo de adquirir el inmueble cuyo dominio útil intenta recuperar, habitaba en él, siendo así que luego lo arrendó, de lo cual la Corte sostiene "que su decisión de mudarse a casa de su hijo debe ser atribuida a la imposibilidad o inconveniencia de continuar viviendo en su propiedad"; en ambos casos no se ampara la pretensión de la parte demandante. Pero, en sentido favorable al actor, tenemos el razonamiento de la resolución recaída en el Exp 689.76, que cita el requisito legalmente preceptuado de habitar en casa alquilada durante un afio probắndolo con los recibos correspondientes, pero luego declara que "no es procedente adoptar una interpretación rígida de ese precepto regla mentario, porque pueden concurrir curcunstancias especiales que impidan la presentación de tales recibos, porque debe atenderse a la finalidad y espíritu de esa norma y porque no es admisible la prueba tasada", premisa sobre la cual se ampara la pretensión del demandante. Así pues, la comprobación de la efectiva necesidad del propietario en este último caso lleva a rebajar los requisitos legales para amparar la demanda, mientras en los dos primeros la estimación sobre la falta de necesidad del propietario hace que su pretensión se desestime por la Corte, a pesar de reunir los requisitos legales

$\mathrm{Si}$ bien puede notarse que la composición de las salas que ven estos tres casos es la misma para los dos primeros y distinta para el último -en el cual sólo interviene un vocal de aquellos que tomaron parte en las otras dos resoluciones-, el razonamiento de los tres casos es consistente. Se ha dado el peso decisorio a la comprobación de la necesidad efectiva del propietario, situando como elemento accesorio la forma establecida por la ley para probarla.

En el segundo tipo de casos referidos el aviso de despedida por casa única, el énfasis parece estar puesto en la instrumentación de un requisito procesal -discutido en los votos singulares- cuyo efecto consiste en no amparar la demanda. Partiendo de la misma premisa general sobre la finalidad de la legislación, en los casos de los Exp. 1346-76 y 1538-76 se exige que la certificación de la casa única, acredite tal condición del propietario "al momento de interposición de la demanda", razón por la cual se declara infundada la demanda en estos casos, en que se actuó en la estación probatoria certificados negativos del registro cuya fecha era posterior a la demanda. En el segundo expediente citado la prueba respecto al demandante era oportuna, pero no lo fue la certificación respecto a su esposa; en el tercer expediente se llega a este extremo: "el certificado de fojas cuarenta, otorgado el nueve de marzo del año en curso, no acredita que a la 
fecha de la demanda, presentada el tres del citado mes, el actor sólo tenía inscrito a su nombre el inmueble a que se refiere". No es posible imaginar mayor rigorismo formal, máxime cuando en este caso el voto singular hace notar que el inmueble en cuestión es uno adquirido con un préstamo destinado a la compra de casa única, condicionado a que el beneficiario habite la misma bajo pena de rescisión del préstamo, situación en la cual deja la solución judicial del caso al actor, al declarar infundada la demanda. Evidentemente, en esta última reso. lución el uso de la exigencia formal conflictúa con el criterio de la necesidad del propietario que alienta la consideración de los dos primeros casos; uno y otro criterio producen resultados opuestos.

Contrariamente a lo que pudiera pensarse, este segundo tipo de razona miento no es formalista. El uso instrumental del argumento formal intenta cerrar el paso a las demandas de aviso de despedida, usando todos los recursos jurídicamente posibles. En vez de intentar proteger al propietario de casa única necesitado de ella, como buscaba el primer tipo de razonamiento, este segundo criterio intenta proteger al inquilino, dada una situación determinada. Los recursos útiles a tal fin son los que resulten pertinentes al caso: desde la exigencia procesal más severa y pegada al texto de la ley, hasta la interpretación amplia de la finalidad implícita en la legislación.

Este segundo tipo de interpretación es tambiến la que parece fundamentar los tres casos comprendidos en la muestra, que no se refieren a aviso de despedi= da. En el primero de ellos (Exp. 1237-76) se sostiene que, "si bien a tenor del documento privado de fojas dieciséis, el departamento fue arrendado como local comercial (...) al destinársele a vivienda no se ha desnaturalizado su finalidad", por lo cual es improcedente la desocupación pretendida por la demandante, basándose en la relación contractual respecto a local comercial. En el Exp. 739-76 se interpreta que al modificarse el plazo y el monto de la merced conicictiva- del contrato de arrendamiento no se produce una novación en lo cual disiente un voto singular-por lo cual aquél permanece regido por las leyes que le eran aplicables al momento de ser contraído, conclusión que en el caso específico mantiene la relación bajo el régimen de protección de las leyes de inquilinato e impide el desahucio intentado por la demandante. Finalmente, el caso más original está en el Exp. $1229-76$ que, tratándose de un grupo de trabajadores que organizados en cooperativa han asumido el manejo de la empresa, sustituyendo a una sociedad en đisolución, interpreta que la situación "no se asimila al caso de una cesación de arrendamiento a favor de tercera persona extraña al contrato de locación-conducción, sino más bien a la institución de la sucesión", por lo cual se declara infundada la demanda de desahucio. 
Luego de haber examinado los razonamientos contenidos en la muestra de ejecutorias supremas sobre arrendamiento en 1976, corresponde una interpretación de los mismos, que intente responder a dos cuestiones centrales: ¿cuál es la relación entre la ley y el juzgador en estos casos? y ihasta dónde es legítima la interpretación innovadora del juez?

Los razonamientos vistos, aún los que sirven para amparar al propietario de casa única en base a su probada necesidad, podrían ser considerados como casos en que el juzgador ha ido más allá de la ley, si bien ha invocado su finalidad como fundamento. Tal crítica no sólo muestra una raíz tradicional y apegada al texto de la ley, sino que padece de superficialidad en la interpretación Efectiva mente, reducir la normatividad al texto legal es devaluar las posibilidades del derecho frente a la realidad, que es mucho más variada, compleja y cambiante que la previsión de una redacción muchas veces anticuada. A menudo, el juzgador debe recurrir a la finalidad objetivamente prevista en la ley -no a un 'espíritu' cuya significación es ambigua y subjetiva- para evitar que nuevos mecanismos, desarrollados bajo la inspiración de "hecha la ley, hecha la trampa", burlen lo que intentó aquélla.

Tratándose del problema del arrendamiento hay una situación social que debe intervenir $y$, sin duda, ha intervenido en la consideración del juzgador en los casos que nos ocupan. Tal situación está caracterizada por una escasez de vivienda, como dicen las sentencias, o una oferta a: alcance de grupos privilegiados. En vista de esto, la legislación ha protegido progresivamente al inquilino; tal es la regla general; la excepción es la protección del propietario de casa uunica. Como quiera que, legalmente, ésta ha sido la única vía a disposición del propietario, de hecho, éste ha fraguado en muchos casos su adecuación al supuesto previsto por la ley, a efecto de recuperar el uso del inmueble y seguir lucrando con la necesidad social, en términos más ventajosos de los obtenidos̉ bajo el arrendamiento original ¿Cómo debe ubicarse el juez frente a este hecho social? Puede cruzarse de brazos en la contemplación de cómo el lado más fuerte en la relación contractual evade con aparente base legal lo dispuesto realmente por la legislación, y quedar a la espera de un nuevo instrumento legal. $O$ puede reinterpretar la situación y la normatividad aplicable según resulte necesario para solucionar el nuevo rostro del conflicto, de acuerdo a como lo intentó la legislación.

Esta segunda actitud es la que parece ser común a las ejecutorias analizadas Una situación coyuntural, en la cual el anuncio de un nuevo régimen legal para el inauilinato precipita a los propietarios a recuperar judicialmente los inmuebles arrendados, es el contexto concreto en el cual se desarrollan los razo- 
namientos de la Corte Suprema. Estos invierten el orden tradicional del razonamiento judicial, según el cual la ley es la premisa mayor y el caso es subsumido en ella para producir un resultado mecánicamente; aquf el juzgador ha prefigurado el resultado socialmente deseable y ha seguido el razonamien to jurídico más adecuado para enderezarse a ese resultado. Se asume así que la ley y los razonamientos jurídicos son sólo instrumentos para la realización de ciertos fines sociales.

Podemos preguntarnos cómo surge esta forma de procesar jurisprudencialmente el conflicto social manifestado, siendo así que la actitud pasiva y legalista ante él ha sido más bien predominante en el poder judicial. Se ha anotado una observación sobre la composición de las salas, como elemento concurrente a explicar cierta diferencia en el razonamiento; el análisis de las ejecutorias muestra que la protección del inquilino, mediante formas instrumentales que incluyen la rigidez formal, es asumida fundamentalmente en los razonamientos de magistrados que vienen de una experiencia alternativa de administración de justicia, la del fuero agrario, en la cual na sólo se ha practicado la tuición en favor del campesino sino que se ha creado innovadoramente a nivel del razonamiento judicial para adecuar la legislación a un profundo proceso de reforma social.

Por eso, no parece casual que los votos singulares que disienten de la exigencia formal respecto a la correspondencia entre el momento de la demanda y la certificación negativa de propiedad, sean de un magistrado que procede, contrariamente, del ejercicio privado de la profesión. Es muy significativa su interpretación acerca de la prueba de la necesidad del propietario, requerida por la ley: "tratándose de una noción subjetiva, el juzgador sólo puede cuestionar la necesidad de habitar en la casa propia en casos ostensibles, que comporten un abuso del derecho" (Exp. 1346-76). Puede advertirse que, si tal fuera el único fundamento para no amparar ciertas demandas, la base legal suficiente está en el Código Civil y serfa inoficiosa la exigencia de la necesidad del propietario a que se refiere el decreto-ley 21168 . En oposición a la interpretación innovadora de la sala, este voto singular restringe la interpretación con dudosa base jurídica.

Lo anterior lleva a subrayar otro aspecto que está bien mostrado por los casos analizados: la imposible neutralidad del juez. La opción por una u otra interpretación no es ciega a los intereses que resultan alternativamente amparados por la sentencia. Esta posición del juzgador, conciente que se le demanda ubicar su función en un conflicto social, está explícitamente revelada en los fallos analizados. Dice la resolución que niega el carácter de locación-conducción sobre local comercial a la que en realidad habra originado un uso de vivienda: 
"CONSIDERANDO: que el enunciado individualista de 'pacta sunt servanda', basado en la aparente igualdad entre las partes, no puede prevalecer en su rigor absoluto frente a los imperativos de la Justicia, que obligan a tener en cuenta las situaciones reales de desigualdad existentes dentro de la sociedad y que informa las normas de derecho social, como las de inquilinato, las cuales, ante el desequilibrio económico, responden al principio de 'pacta sunt dirimenda', que faculta al Juzgador para determinar y corregir el contrato, decidiendo la colisión entre el interes individual y el social a favor del segundo" (Exp. 1237.76).

Con lo cual, la superación de la formal igualdad entre las partes no es una mera consideración doctrinaria sino una premisa de evidente significación en el conflicto social.

La legitimidad de esta tarea innovadora, su preservación de la arbitrariedad, se encuentra en la forma en que interprete o busque en la sociedad la vigencia de un interés dado como fundamento real para optar por uno $u$ otro criterio de interpretación. Si la norma jurídica es tal en cuanto reúne consenso y coerción, estas características también concurren a la sentencia como fuente de legitimidad. Es tarea creativa del juez buscar tal interés social, en una realidad evolutiva, cambiante y con variables equilibrios de fuerzas. Tal rol está bien expresado en el fallo sobre el caso de los trabajadores que, cooperativizados, asumen la empresa, y a los cuales la Corte Suprema les reconoce haber sucedido jurídicamente en el arrendamiento a la sociedad propietaria de la empresa:

"el juez, cuya función es administrar justicia, no puede permanecer indiferente a los cambios que ocurren en la realidad donde actúa y, por el contrario, es su deber aplicar las leyes en armonía con esas transformaciones; que desde hace tiempo prevalece en la doctrina y en la legislación comparada el concepto de que la empresa es una comunidad de trabajo y que a ella concurren como sujetos esenciales empresarios y trabajadores, de donde resulta que el trabajador no es persona ajena a la empresa; que, asimismo, es oportuno tener presente que toda empresa, en cuanto es fuente de trabajo, cumple una función social, por lo que su adecuado desenvolvimiento interesa no sólo a sus componentes y a quienes mantienen relaciones con ella sino a la Sociedad, a cuyo bienestar coadyuva y por ende al Estado mismo" (Exp. 1229-76).

Esta consideración de lo atendible según un interés social concreto es lo que, al mismo tiempo, puede precaver al juez respecto a que su función, menos apegada a la ley, resulte en servicio del gobierno; es decir, que la fuente legal sea 
en los hechos sustituída por la fuente dei poder, riesgo muy marcado en todo intento de hacer prevalecer la justicia por encima de la ley, y en el cual ha ca1do, entre nosotros, por lo menos un presidente de la Corte Suprema:

"si el deredio riene a ser a realidad en acción y. el ideal s obtexi siempre la justícia, ésta debe primar en todo caso sobre aquel y establecerse por las vías de la interpretacion jurisprudencial, a fin de lograr el sano equilibrio que debe normar la relación sociojuridica actual, por ser fuente indiscutible del derecho, porque en el momen to histórico que vivimos, segun el Estatuto que nos rige, ninguna ley puede ser incompatible con los altos fines de la Revolución (José García Salazar, Memoria del año judicial 1973, El Pe ruzmo. $19374)$

Un obvio comentario final. Los casos muestran, del modo más claro y contundente, que la jurisprudencia es efectiva fuente de derecho, no sólo en cuanto resuelven coerciblemente el curso de las relaciones jurídicas entre partes individuales, sino en tanto que su dirección determina aquello que los abogados predecirán a su cliente como lo obtenible a través de una solución judicial, para que cada uno sepa a qué atenerse. Tal carácter de la jurisprudencia no es nuevo; siempre ha sido así; lo novedoso es que, en vez de esconder su labor en el mero cumplimiento o en la aplicación mecánica de la ley, el juzgador empieza a asumir hoy, conciente y explícitamente, el rol que cumple. 